\title{
La argumentación a favor del trabajo sexual y sus implicaciones éticas
}

\author{
Ma Concepción Gimeno Presa* \\ Recibido: 4 de diciembre de 2016 • Aprobado: 4 de julio de 2017 \\ https://doi.org/10.22395/ojum.v17n33a3
}

\section{RESUMEN}

Cómo deben actuar los Estados democráticos modernos ante la práctica de la prostitución constituye actualmente una cuestión polémica. Dentro del movimiento feminista la forma de resolver este problema ha generado una brecha que parece difícil de resolver. Las partidarias de que los gobiernos regularicen la prostitución como una relación laboral más justifican su postura con argumentos que consideran sólidos jurídicamente y neutrales desde el punto de vista ético. Afirman que las razones dadas para prohibir la prostitución y para no considerarla una actividad laboral son razones morales. A su vez, sostienen que los Estados democráticos de derecho no tienen como función el imponer creencias éticas a sus ciudadanos sino salvaguardar los derechos de los mismos, en especial el derecho a la libertad individual. En el trabajo recojo los argumentos esgrimidos a favor y en contra de que la prostitución deba regularizarse como un trabajo y muestro cómo el razonamiento de las representantes del feminismo a favor del trabajo sexual está construido sobre una teoría ética que se presupone como válida y que, por lo tanto, no es objeto de discusión. Sostengo que la forma más adecuada de llegar a un consenso sobre este tema sería plantear abiertamente y de forma previa al debate político y jurídico, una reflexión ética sobre qué postulados y que concepción moral de la sexualidad nos parecen más valiosos para tratar este complejo problema.

Palabras clave: Argumentación jurídica, razones morales, teorías éticas, derecho de libertad, derecho de igualdad, prostitución.

\footnotetext{
El presente trabajo de investigación ha sido elaborado durante los años 2016 y 2017 dentro del proyecto de investigación Conflictos de derechos y producción normativa, DER2016-74898-C2-2-R, financiado por el Mineco y Feder.

* Licenciada en Derecho por la Universidad Complutense de Madrid (España), doctora en Derecho por la Uned, Madrid (España). Titular de Filosofía del Derecho. Facultad de Derecho, Universidad de León, España. Correo electrónico: mcgimp@unileon.es.Código Orcid: 0000-0003-1549-4683
} 


\title{
Argument in Favor of Sexual Work and Ethical Implications
}

\begin{abstract}
How modern democratic states should deal with the practice of prostitution is now a controversial issue. Within the feminist movement, the way to solve this problem has created a gap that seems difficult to solve. Advocates of governments regularizing prostitution as an additional employment relationship justify their position with arguments that they consider legally solid and ethically neutral. They claim that the reasons given for prohibiting prostitution and not considering it as a work activity are moral reasons. In turn, they argue that democratic states governed by the rule of law do not have the function of imposing ethical beliefs on their citizens but of safeguarding their rights, especially the right to individual freedom. In this work, arguments for and against that prostitution should be regularized as a work Re mentioned and show how the reasoning of the representatives of feminism in favor of sex work is built on an ethical theory that is assumed to be valid and therefore not the object of discussion. I state that the most appropriate way to reach a consensus on this issue would be to openly and in advance of the political and legal debate, raise an ethical reflection on what postulates and what moral conception of sexuality seem to us to be the most valuable concept in dealing with this complex problem.
\end{abstract}

Keywords: Legal argument, moral reasons, ethical theories, freedom right, equality right, prostitution.

\section{A argumentação a favor do trabalho sexual e suas implicações éticas}

\section{RESUMO}

A forma como os Estados democráticos modernos devem atuar diante da prática da prostituição constitui atualmente uma questão polêmica. Dentro do movimento feminista, a forma de solucionar esse problema gerou uma brecha que parece difícil de resolver. As partidárias de que os governos regularizem a prostituição como uma relação trabalhista a mais justificam sua postura com argumentos que consideram juridicamente sólidos e neutros do ponto de vista ético. Afirmam que as razões dadas para proibir a prostituição e para não considerá-la uma atividade profissional são razões morais. Por sua vez, alegam que os Estados democráticos de direito não têm como função impor crenças éticas a seus cidadãos, mas resguardar os direitos deles, em especial o direito à liberdade individual. No trabalho, analiso os argumentos levantados a favor da regularização da prostituição como um trabalho e contra ela, e mostro como o raciocínio das representantes do feminismo a favor do trabalho sexual está construído sobre uma teoria ética que se pressupõe como válida e que, portanto, não é objeto de discussão. Defendo que a forma mais adequada de chegar a um consenso sobre esse tema seria expor, abertamente e de forma prévia ao debate político e jurídico, uma reflexão ética sobre quais princípios e qual concepção moral da sexualidade nos parecem mais valiosos para tratar esse complexo problema.

Palavras-chave: Argumentação jurídica; direito de igualdade; direito de liberdade; prostituição; razões morais; teorias éticas. 


\section{INTRODUCCIÓN}

Este trabajo persigue dos objetivos: el primero consiste en recoger y sistematizar los principales argumentos con los que se está justificando, dentro del mo vimiento feminista, la regularización de la prostitución como una actividad laboral. El segundo objetivo es mostrar que el razonamiento desarrollado por la postura pro regularización no es, tal y como pre tenden sus partidarias, un razonamiento neutral desde el punto de vista ético ${ }^{1}$. Las partidarias de considerar la prostitución como un trabajo sostienen que esta es la postura que deberían adoptar los Estados sociales y democráticos modernos cuya obligación es salvaguardar el derecho de libertad y el principio de autonomía de las personas manteniéndose neutrales desde el punto de vista ético. Perseguir esta práctica o no reconocerla como una actividad laboral implicaría, según este grupo, no solo vulnerar dichos derechos, sino extralimitarse en las obligaciones que los Estados deben cumplir y ello porque supondría la imposición a sus ciudadanos de unas determinadas creencias morales como válidas en detrimento de otras.

La tesis que defiendo es que el debate sobre la prostitución en el seno del feminismo parece imposible de resolver porque requiere de un previo debate

\footnotetext{
En este trabajo se utilizará dos expresiones diferentes para identificar a las partidarias de regularizar la prostitución como un trabajo: pro-regularización y pro-derechos. Esta última denominación es usada por ser la forma en la que el propio grupo prefiere ser denominado, aunque ha generado polémica entre las partidarias del feminismo abolicionistas, quienes consideran que ellas también defienden los derechos de las prostitutas.
}

ético que se está evitando por todas sus participantes. En dicho debate se debería reflexionar y no establecer como válida de antemano cuál es la teoría ética que se debe aplicar para tratar este problema, se debería analizar cuál es la naturaleza de la sexualidad humana, cuáles son las posibles concepciones acerca del deseo sexual y si los argumentos construidos desde una moral general sirven para comprender las relaciones sexuales o es necesario construir nuevas razones amparadas en una moral sexual específica capaz de vencer las contradicciones y limitaciones que hasta ahora la moral sexual contemporánea pueda estar originando.

El trabajo no pretende en modo alguno defender o defenestrar ninguna posición al respecto, sino únicamente aclarar cuáles son las razones con las que se está justificando la posición que los Estados deben adoptar actualmente ante la prostitución y demostrar que el razonamiento a favor del trabajo sexual implica juicios éticos que no están siendo abiertamente debatidos.

Para llevar a cabo esta tarea he dividido el trabajo en dos partes. En la primera reconstruiré los principales argumentos con los que se está defendiendo la regularización de la prostitución como un trabajo sexual y mostraré cómo la principal crítica que las partidarias de esta postura hacen a las abolicionistas consiste en afirmar que su respuesta se basa en argumentos de naturaleza ética, que carece de objetividad y que supone la imposición de una determinada moral. En la segunda parte, mostraré como la solución aportada por el 
grupo pro-derechos está justificada también en un razonamiento que no es para nada neutral desde el punto de vista moral.

Considero que este análisis puede resultar útil para entender la brecha que el tema de la prostitución ha abierto dentro del movimiento feminista y puede servir para dar un paso atrás en la forma de plantear este tema tomando consciencia de la importancia que la filosofía moral tiene a la hora de construir el tipo de sociedad en la que se quiere vivir.

\section{EL TRABAJO SEXUAL Y SU JUSTIFICACIÓN}

Una de las cuestiones que más debates está suscitando en la actualidad versa sobre qué respuesta jurídica debe dar el Estado a la prostitución consentida. Esta cuestión está vigente en las agendas políticas de los gobiernos y es objeto de discusión teórica en numerosos países. En este epígrafe voy a analizar los argumentos aportados por los movimientos feministas dentro del debate teórico para justificar las principales respuestas con las que pretenden dar solución al problema. La selección no es arbitraria. Considero que los mayores logros en la lucha por la igualdad de las mujeres se han conseguido históricamente gracias a las reivindicaciones llevadas a cabo desde estos movimientos; además, son los que han mostrado un mayor interés en el tema de la prostitución los que más argumentos desarrollan y los que más sólidamente lo han analizado y debatido. Si bien dentro del término "feminismo" ha habido y hay muchas manifestaciones diferentes y entre ellas hay discrepancias conceptuales, metodológicas y epistemológicas, todas sus variantes tienen un punto de partida común y un objetivo que las une: la lucha por conseguir una sociedad más igualitaria y justa donde las mujeres tengan reconocidos, garantizados y puedan ejercer en igualdad de condiciones los mismos derechos que los hombres ${ }^{2}$. Sin embargo, en relación con la cuestión que planteo en este trabajo se da una peculiaridad: las respuestas feministas son tan diferentes que parece imposible ni siquiera acercarlas. Mientras una parte, a la que se identificará en adelante como grupo abolicionista, defiende la abolición (erradicación) de cualquier tipo de prostitución, la otra (en adelante grupo pro-derechos) opta no solo por su legalización cuando se trata de prostitución consentida sino también por su consideración como una actividad laboral más ${ }^{3}$. Lo asombroso es que las dos posiciones apoyan la validez de sus respuestas afirmando que las mismas garantizan el ejercicio de los derechos y libertades fundamentales, en especial de los derechos de libertad y de igualdad establecidos en los ordenamientos jurídicos. A la hora de criticar a sus contrincantes, la mayoría de los partidarios de la postura pro-derechos aluden a que

\footnotetext{
Son muy numerosos los estudios acerca del movimiento feminista y sus variantes. Para un análisis de la historia de estas variantes y sus implicaciones en el ámbito jurídico ver: Valcárcel (1991,1997, 2001); Pitch (2010), Ruíz (2001), Unzueta (1992); Gamba (2008), Rorty (2003), Loviband y Sefchovich (1992).

3 La expresión pro-derechos ha sido acuñada por las propias partidarias del grupo pro-legalización. No es una denominación con la que las abolicionistas estén de acuerdo puesto que consideran que también ellas luchan por los derechos de las prostitutas.
} 
los argumentos abolicionistas encierran razones morales, mientras que ellos ofrecen una solución basada en argumentos moralmente neutros y este tipo de argumentos son los únicos que deben tener en cuenta los Estados democráticos y laicos a la hora de regular jurídicamente los problemas sociales. Además, alegan que los partidarios del abolicionismo adoptan una posición de superioridad moral cuando construyen sus argumentos, y las feministas no deben erigirse en el estandarte de la moral colectiva ${ }^{4}$.

Para sistematizar los argumentos con los que se justifican cada una de las respuestas los he dividido en dos grupos: en uno recojo aquellos con los que se defiende la legalización de la prostitución y se critica la imposición de medidas sancionatorias por parte del Estado con el fin de erradicarla; en el segundo, figuran los argumentos con los que se justifica la consideración de la compraventa de sexo como una actividad laboral. En cada uno de estos grupos he seguido el siguiente orden expositivo: recojo los argumentos dados por la postura pro-derechos a favor de su respuesta; a continuación, indico cuáles son las réplicas que el grupo abolicionista da a cada uno de esos argumentos y finalizo mostrando cómo

4 Esta crítica se puede ver en: Juliano (2005, p. 87), Maqueda Abreu (2006), Holgado (2008, p. 9); Rodríguez Martínez (2008, pp. 48-49); Juliano (2008, pp. 119-127); Holgado (2008a, p. 156), García (2007, p. 29). Por su parte, Rodríguez (2008) critica a los Estados cuando, bajo la apariencia de normas neutrales, niegan derechos a las prostitutas (p. 258). También critican a las abolicionistas por estas mismas razones, otros estudiosos de la cuestión ajenos al movimiento feminista, como es el caso de De Lora (2007, pp. 460-469). el grupo pro-derechos se defiende de dichas críticas.

Antes de iniciar el análisis de las argumentaciones dadas, es necesario hacer una serie de puntualizaciones conceptuales. Cuando hablo de "prostitución consentida" me refiero a la siguiente práctica social: la compra y venta de relaciones sexuales a cambio de un dinero entre dos personas adultas y capaces, pactadas voluntariamente por ambas. Dejo fuera de esta discusión el estudio de otras prácticas sociales relacionadas con la prostitución que en ocasiones son incluidas en el ámbito del significado de ese término, como es el caso de la pornografía. También quedan fuera de este debate las posibles respuestas jurídicas a otras formas de prostitución como la infantil o las soluciones a problemas relacionados habitualmente con la compraventa de sexo como son el tráfico de mujeres, la trata de personas, el comercio con drogas, las mafias, etc. En todos estos casos, la prostitución va unida a la comisión de delitos tipificados en los códigos penales no existiendo controversia teórica, ni dentro ni fuera del feminismo, en relación con la persecución jurídica que deben sufrir los mismos ${ }^{5}$.

Existe un punto de confluencia dentro de las posturas feministas. Para todas ellas el Estado no debe sancionar a las prostitutas. Salvo en este extremo, la discrepancia

\footnotetext{
Junto con el abolicionismo y la regularización como un trabajo hay una tercera respuesta, denominada reglamentismo que no es objeto de estudio en este artículo al no tener adeptas dentro de los movimientos feministas.
} 
es absoluta, incluso respecto de las razones alegadas para sostener esa idea.

\section{ARGUMENTOS A FAVOR DE LA LEGALIZACIÓN DE LA PROSTITUCIÓN}

Las posiciones a favor de los derechos de las trabajadoras del sexo consideran que el Estado tiene la obligación de legalizar la prostitución. Esto significa que no debe dictar normas cuyo objetivo sea castigar a las personas implicadas en esta práctica siempre que la misma se realice con el consentimiento de todas ellas. Por lo tanto, los grupos pro-derechos sostienen que no toda compra-venta de sexo es el resultado de una acción coactiva y que no todas las prostitutas son víctimas. Justifican esta afirmación recogiendo las declaraciones de las propias mujeres que se dedican a esta actividad. Según sus propias palabras, la mayoría de ellas se introdujeron en la prostitución por necesidades económicas, todas admiten que fue una decisión dura de tomar, pero muchas manifiestan en la actualidad su deseo de seguir ejerciendo la prostitución. Los motivos pueden ser muy variados, pero en gran medida son de carácter económico: la prostitución les permite ganar más dinero y en menos tiempo que si se dedicasen a otra actividad; además, les confiere la facultad de gestionar su dinero, su tiempo y la forma y el modo de desarrollarla; es una forma de ganarse la vida para poder mantenerse ellas y sus familias, etc. (Espejo, 2008); (Maqueda, 2008/2009), (Garaizábal, 2006, 2009), (López Riopedre, 2012); (Mestre, 2008), (Romalho, 2012), (Lorenzo, 2008).
El grupo abolicionista, por su parte, considera que no se puede hablar en ningún caso de prostitución libremente consentida, ya que las mujeres que se dedican a ella lo han hecho debido a una necesidad imperiosa. Aducen que no hay libertad de elección cuando la situación en la que se encuentran esas mujeres impide que haya opciones entre las cuales elegir. Una cosa, sostiene este grupo, es hablar de prostitución voluntariamente aceptada y otra muy distinta de prostitución libremente aceptada (Falcón, 1992, 2012, 2014), (Barry, 1988), (Giménez, 2008).

Ante esta réplica, los grupos pro-derechos estiman que, si se parte de un concepto tan amplio de libertad, nada en la sociedad es libremente elegido puesto que siempre existen circunstancias condicionantes. Cuando se escoge un trabajo no siempre es el que se desea puesto que las circunstancias sociales, políticas, económicas, familiares determinan y limitan todas las decisiones posibles.

Qué características debe tener una decisión para afirmar que se ha tomado libremente es una cuestión aún muy discutida en el ámbito filosófico, psicológico y jurídico. El debate sobre qué debe hacer el Estado respecto de la prostitución se tornaría inútil si no se admitiese al menos que junto a personas a las que de forma violenta y en contra de su voluntad se las coacciona para que ejerzan la prostitución, conviven otras que son plenamente conscientes de lo que hacen y deciden hacerlo sin que nadie las intimide o coaccione. Hay una parte del abolicionismo que se muestra dispuesta a aceptar esta 
diferenciación, aunque señalan que, a pesar de ello, las opciones con las que cuentan las prostitutas son demasiado limitadas y a veces "solo pueden optar entre vender su sexualidad o malvivir" (Rubio, 2008, p. 88) ${ }^{6}$.

Por otra parte, los grupos que abogan por la legalización piensan que las mujeres tienen derecho a disponer de su cuerpo como estimen oportuno. Esta facultad "forma parte del ejercicio de su derecho de libertad" (Espejo, 2008, p. 138). Entre los usos que pueden darle está el de comercializar con su sexualidad. Admiten que nuestra sociedad es una sociedad de consumo, capitalista y mercantilizada, y que el sexo debe interpretarse dentro de este contexto por lo que no se justifica que no se pueda comprar y vender.

Este argumento es discutido por la posición abolicionista que ve en la mercantilización del cuerpo un problema ético reprobable ${ }^{7}$ Objetan que de igual forma que el Estado prohíbe la venta de órganos, debe prohibir la venta del cuerpo de las mujeres. Para los grupos pro-derechos esta réplica incurre en un error al identificar cuerpo con sexualidad. Afirman que con la prostitución no se compran ni se venden los cuerpos de las personas, simplemente se usan para prestar un servicio.

6 A este respecto, Gimeno (2012) sostiene: "Si el feminismo anti prostitución continúa negándose a distinguir entre prostitución forzada y voluntaria, será imposible conseguir un acuerdo para exigir un mayor compromiso contra la primera" (p. 64).

7 La mercantilización del cuerpo de la mujer no solo se puede apreciar en la práctica de la prostitución. Se trata de un fenómeno extendido en nuestra sociedad Cobo (2013). La cosificación del sexo es analizada también por: Aucía (2008, pp. 148 149).
Lo que se vende es un servicio sexual y una vez finalizado este, el cuerpo sigue perteneciendo a la prostituta. Por lo tanto, lo que las mujeres hacen cuando se prostituyen es usar su capacidad sexual para obtener una ganancia. Alegan que de igual forma que un psicólogo presta sus conocimientos, una abogada presta un servicio de defensa o un operario "arrienda" sus manos para hacer un trabajo, las prostitutas comercian con su sexo. Una vez más justifican esta afirmación con las historias de vida de las personas que se prostituyen en las estas afirman que su función es similar a la que efectúan las abogadas, "con la sola diferencia de que ellas deciden a quién prestar el servicio y a quién no, mientras que las abogadas tienen que defender en muchas ocasiones a personas que son delincuentes sabiendo que son culpables" (Holgado, 2008, p. 27) ${ }^{8}$. El grupo pro-derechos considera que ver en el uso de la sexualidad un problema moral y no verlo en otras prácticas sociales análogas tiene solo un origen prejuicioso frente a la sexualidad, la cual "es sacralizada de forma no justificada" (Garaizábal, 2006, p. 67). En este sentido, afirman que cada uno puede tener las creencias morales que desee, pero que no debe imponérselas a los demás (Maqueda, 2006).

La obligación de los Estados democráticos es respetar y garantizar el derecho de libertad de las personas. La prohibición de la prostitución consentida impediría que las mujeres pudieran ejercerlo. Con

\footnotetext{
En contra de que la mayoría de las prostitutas sean libres para elegir a sus clientes ver: De Marneffe (2010, p. 21).
} 
base en este argumento, los grupos pro derechos manifiestan que carece de fundamento la imposición de sanciones tanto a las prostitutas como a sus clientes. Solo se debe perseguir la prostitución forzada. Para las abolicionistas, si bien las prostitutas no deben ser castigadas al ser siempre personas que sufren violencia y explotación, sí lo deben ser los compradores de sexo en cuanto que estos llevan a cabo actos de dominación que atentan contra la dignidad de las mujeres tratándolas como cosas y no como personas. Los grupos pro-derechos critican con dureza la visión que de los clientes aportan las partidarias de la legalización. Sostienen que estas los consideran como un todo homogéneo cuando en realidad hay muchos tipos de clientes y no todos llevan a cabo actos violentos ni actos de dominación. Teniendo en cuenta la opinión de las mujeres que se prostituyen, afirman que los hombres en la actualidad acuden a la prostitución por muchos motivos: estatus social, ocio, buscando una relación esporádica para "satisfacer un deseo sexual de forma fácil, rápida y sin compromisos, buscando compañía, o para experimentar nuevos placeres o técnicas sexuales" (Holgado, 2008, p. 156). Generalizar que todo cliente busca dominación es incurrir en un grave error como lo es también que las abolicionistas no tengan en cuenta ni la existencia de prostitución masculina ni el hecho de que haya mujeres que sean consumidoras de sexo pago. Argumentan a los efectos de negar que la prostitución sea siempre una relación de dominación del hombre sobre la mujer, que "la existencia, aunque en menor grado, de otros tipos de prostitución, prueba que esta práctica social no implica en todo caso un trato unidireccional de dominio del hombre sobre la mujer" (Garaizábal, 2008, p. 106).

Pese a todas estas justificaciones aportadas para probar que la prostitución no implica necesariamente la subordinación de la mujer frente al hombre, las abolicionistas siguen considerando que la práctica en sí de la prostitución juega un papel simbólico en la sociedad; se trata de una relación donde las partes no actúan en plano de igualdad y donde los roles de género resultan reforzados: mujer pasiva y dominada al servicio de los deseos de los hombres, hombre superior a la mujer que la usa para su provecho9. No están de acuerdo en el método usado por el grupo pro-derechos para justificar que la relación no es desproporcionada y afirman que el sentido de la prostitución no puede establecerse únicamente por la consideración que de la misma tengan las mujeres que se prostituyen. La forma en la que ellas viven su actividad no significa que esta no pueda ser interpretada y tenga un valor distinto al que los sujetos involucrados le dan. Las mujeres maltratadas, arguyen, también defienden a sus maridos y no se sienten en muchas ocasiones en estado de sumisión. La opinión de los partícipes no es definitoria para valorar la prostitución. Además, muchas de estas historias de vida muestran cómo los varones acuden al sexo pagado para sentirse más machos y para que se les reconozca y se les valore como hombres.

La importancia del valor simbólico de las prácticas sociales ha sido objeto de análisis por: Frazer (1996, pp. 18-40) y por Ngozi Adichie (2015, p. 1). 
Que ellas consideren que están representando solo un papel no significa que no estén siendo objeto de un trato abusivo. Los Estados no deben legalizar esta práctica; su objetivo debe ser erradicarla porque la legalización significa normalizar esta forma de vida sexual, y normalizarla es aceptarla como válida lo que implica situar a las mujeres en un plano desigual respecto del hombre ${ }^{10}$. En lo que se refiere a la existencia de prostitución masculina, las abolicionistas consideran que esta modalidad es muy diferente a la femenina: el número de hombres que venden su sexualidad es mucho menor que el de mujeres; sobre ellos recae un estigma más leve, sus clientes suelen ser otros hombres con lo que no se rompe la relación de dominio masculino sobre lo femenino; además, muchos de los que se dedican a ella son transexuales que simbolizan el rol femenino en la relación. Por otra parte, cuando las mujeres son las que pagan por una relación sexual lo hacen generalmente movidas por motivos distintos a los de los hombres. Suelen buscar afecto y acuden a la prostitución buscando una relación diferente a la que busca aquel. Por todo ello, las abolicionistas afirman que la existencia de otras formas de prostitución no es suficiente para cambiar la valoración de la institución y el significado simbólico que tiene en la sociedad.

10 La desigualdad entre hombres y mujeres que traería consigo la legalización de la prostitución es examinada por De Miguel (2015, pp. 149-178). En contra de la legalización por razones similares fuera del movimiento feminista se manifiesta Brufao Curiel (2008). Pateman (1995) afirma que con la legalización de la prostitución lo que se legitima es "la ley del derecho sexual de las mujeres, es el reconocimiento público como amos sexuales de las mujeres" (p. 283).
Si las abolicionistas critican el método usado por sus contrincantes para justificar sus argumentos a favor de la legalización, las pro-derechos tampoco están de acuerdo ni con los argumentos aportados por aquellas ni con el método elegido. Piensan que la argumentación para justificar el valor simbólico de la prostitución parte de la idea de que solo existe un tipo de hombres y un tipo de mujeres y es a su juicio un fallo homogeneizar bajo un mismo rótulo a una colectividad, máxime cuando esto supone crear una dicotomía absurda: hombre siempre malo y mujer siempre buena o víctima (Wijers: 2004) Por otra parte, tampoco les parece acertado que las abolicionistas analicen el problema desde una posición externa al mismo, ignorando la voz de las prostitutas al considerarlas personas sin capacidad para tener una opinión. El método que usan y su actitud paternalista les impiden tener una visión real de la prostitución. En la interpretación que hacen de esta práctica no tienen en cuenta el contexto que la rodea; tampoco tienen en consideración que en ella intervienen relaciones de dominio que no obedecen a razones de género, pero que la dotan también de significado como son la raza, la clase, el estatus social y el económico. Además, cuando las abolicionistas alegan que la práctica atenta contra el derecho de dignidad de las mujeres no aportan razones que justifiquen esta afirmación, ni son capaces de explicar en qué medida el sexo

\footnotetext{
"Por su parte Rodríguez (2008) sostiene que "considerar a las prostitutas siempre como víctimas es una postura conservadora y moralista" (p. 49). En contra de considerar a las mujeres como un grupo homogéneo Mohanty (1990).
} 
pago es vejatorio para las personas y no lo son otras prácticas como la pornografía que de hecho están legalizadas (Maqueda, 2006). Por todo ello, consideran que la visión de la prostitución que hacen las abolicionistas es pobre, está sesgada y obedece a razones meramente morales (Pheterson, 1992) ${ }^{12}$.

Los grupos pro-derechos concluyen afirmando que legalizar la prostitución consentida no solo no vulnera el ordenamiento jurídico, sino que el no hacerlo implica menoscabar las decisiones libremente tomadas por las mujeres y esto es una violación de su derecho de libertad reconocido como un derecho fundamental en los textos constitucionales.

Junto a los argumentos a favor y en contra de la legalización los diferentes movimientos feministas desarrollan justificaciones para demostrar los efectos que conllevaría la imposición de sanciones a los consumidores de sexo pago. Esta medida, tal y como ya he expuesto, es solicitada desde las posiciones abolicionistas las cuales la consideran, además de justa, eficaz para erradicar la prostitución. Sin embargo, las posturas contrarias estiman que la misma conlleva tratar a los clientes como delincuentes cuando no hacen daño a nadie; es más, gracias a ellos, muchas mujeres consiguen dinero para vivir $^{13}$. Estas posturas consideran

12 J. Montero y B. Zabala (2006) critican por esta razón a Lidia Falcón cuando sostiene que "las víctimas de la prostitución no pueden saber ni entender cómo se realiza una sexualidad placentera y gratuita" (p. 102).

13 La culpabilidad del cliente según las abolicionistas es evidente si tenemos en cuenta que en el siglo que, si los Estados castigan a los clientes de la prostitución, se extralimitarían en sus funciones al penalizar acciones que no causan daño alguno por el hecho de aceptar como válido un juicio moral que las tacha de incorrectas. Pero, además, y con independencia de estas consideraciones, el grupo pro-derechos no ve que las sanciones puedan ayudar a que la prostitución desaparezca (Villacampa, 2012), (Maqueda 2006, 2010), (Holgado, 2008). Fundamentan su escepticismo en razones históricas mostrando cómo en los períodos históricos en los que se han implementado, la prostitución ha sobreviviendo al margen de la ley y en peores condiciones; además, han aumentado los delitos asociados a esta práctica social (trata de mujeres, explotación y tráfico ilegal, entre otros). Las medidas coercitivas hacen a las prostitutas personas más vulnerables; impiden que pacten con tranquilidad las condiciones de su servicio y les niega la única fuente de ingresos que tiene la mayoría de ellas. El hecho mismo de que se implementen castigos aumenta su estigma con lo que son vistas por la sociedad como mujeres inmorales y perjudiciales sin que hayan llevado a cabo ninguna acción dañina ${ }^{14}$. De esta forma la intervención de los Estados asienta

XXI los hombres son conscientes de que detrás de la prostitución se esconden delitos como la trata de personas y la explotación. Sin embargo, cuando acuden al sexo de pago ignoran estas circunstancias, es más acuden a ella en la mayoría de las ocasiones buscando una relación sexual cargada de subordinación y sumisión por parte de la prostituta. En este sentido: González (2012, p. 16) y Torres San Miguel (2008).

14 Un estudio completo sobre el estigma que sufren las prostitutas se puede ver en: Pheterson (1996). 
una interpretación negativa de la prostitución haciéndose eco de los prejuicios morales que hacia el sexo y la forma de ejercerlo tiene una parte de la sociedad (Arella, 2007).

\section{ARGUMENTOS A FAVOR DEL "TRABAJO SEXUAL"}

El debate habido en el seno del feminismo en relación con la prostitución consentida se acentúa aún más cuando las partidarias de su legalización consideran que no solo el Estado debe legalizarla en pro del derecho de libertad de las mujeres, sino que, además, debe considerarla como una actividad laboral similar a la prestación de un servicio (Maqueda, 2009) $)^{15}$. Su reconocimiento como un trabajo garantizaría no solo el derecho de libertad de las mujeres sino también su derecho de igualdad e incluso el derecho de libertad de empresa, reconocidos todos ellos en los textos legales en vigor. Justifican estas afirmaciones alegando que la prostitución es una institución que debe ser interpretada en el contexto en el que se desarrolla. Las sociedades actuales son sociedades donde se ofrecen bienes y servicios, y en ellas todo se puede comprar y vender. El derecho avala y regula estas relaciones mercantiles atendiendo a las demandas de sus ciudadanos. La prostitución no es diferente a la prestación de un servicio. Lo único que cambia es el tipo de servicio que se ofrece. Hay personas que venden sus conocimientos, otras sus habilidades para efectuar determinadas tareas (pintar, arreglar una tubería, limpiar.... );

15 En contra del carácter neutro del trabajo sexual: Lipszyc (2003). las prostitutas venden su capacidad y sus destrezas para dar placer sexual ${ }^{16}$.

Las prestaciones de un servicio a cambio de un dinero están reconocidas por el Estado como una actividad laboral. Para que sean así consideradas se exige una serie de requisitos: 1.- existencia de una relación libremente pactada entre las partes, 2.- que en esa relación las dos partes salgan beneficiadas, 2.- que la actividad constituya una fuente de ingresos para la persona que presta el servicio, o sea que no sea una actividad gratuita, 3.- que la prestación no dañe a terceros.

La prostitución consentida cumple con todas estas características. No se puede alegar la dureza que esta actividad conlleva para la prostituta, en cuanto que hay ocupaciones igual de sacrificadas, e incluso más, que son reconocidas por el Estado como trabajos. "La recogida de fresas, el trabajo doméstico, limpiar letrinas pueden resultar iguales de gravosos que la prostitución para muchas personas" (Agustín, 2002, p. 17). Tampoco consideran válido negarle su carácter laboral aduciendo que es una relación asimétrica ya que en los trabajos por cuenta ajena la simetría tampoco existe, ni afirmando que en ella se explota a las trabajadoras y supone un trato degradante o inhumano porque "la explotación está presente en muchos otros trabajos" (Espejo, 2008, p. 128). El hecho de que estos se regulen

16 La necesidad de interpretar la prostitución dentro del contexto social donde se desarrolla es alegada entre otras por: Rodríguez (2008, pp. 41 42, 45); Mestre (2008, p. 55). 
jurídicamente es lo que permite evitar los tratos abusivos.

De acuerdo con la CE todos los españoles tienen el deber de trabajar y el derecho al trabajo, a la libre elección de profesión u oficio, a la promoción a través del trabajo y a una remuneración suficiente para satisfacer sus necesidades y las de sus familias sin que haya discriminación por razón de sexo (artículo 35). Además, los poderes públicos están obligados a fomentar una política que garantice la formación y readaptación de los profesionales y a velar para que puedan desarrollar sus proyectos de vida ${ }^{17}$. A este respecto, Nancy Frazer (1996) afirma que el derecho de igualdad exige a los Estados democráticos igual respeto y reconocimiento para cualquier plan o trayectoria de vida elegida tanto por los hombres como por las mujeres, planes que deben ser considerados valiosos con independencia de cuáles sean estos. La prostitución es una forma como otra de ganarse la vida, para muchas mujeres, y "para algunas personas, como los transexuales, es, quizá, la única forma de hacerlo" (Espejo, 2008, p. 134). Su reconocimiento a efectos laborales garantizaría el ejercicio de sus derechos fundamentales. Por el contrario, no reconocerla como tal implicaría fomentar la desigualdad entre los ciudadanos considerando a unos como trabajadores y a otros no cuando están realizando tareas análogas. Además, también aumentaría la desigualdad entre hombres y mujeres al no permitir a

17 A este respecto Mestre $(2007,36)$ considera que "el principio de igualdad de respeto exige igual respeto y reconocimiento para cualquier plan/trayectoria de vida elegida por hombres y mujeres". estas últimas, que son las que se dedican mayoritariamente a la prostitución y que además tienen peor acceso al mercado laboral, que puedan abrir nuevos espacios en el terreno laboral donde desarrollarse. Alegan también que el no reconocimiento del trabajo sexual imposibilita a muchas mujeres acceder a la condición de ciudadanas y, en una sociedad donde el trabajo es el requisito para ello, negarles esta condición es impedir que tengan los derechos sociales y económicos que la ciudadanía conlleva (Agustín, 2008), (Montero y Zabala, 2006), (Holgado, 2008). Siendo el trabajo la fórmula para que los ciudadanos queden incluidos en el grupo social, no reconocer la prostitución como trabajo provoca otra consecuencia negativa: destinar a estas mujeres a la exclusión y a la invisibilidad convirtiéndolas en personas de segunda clase (Lorenzo, 2008).

Junto a todos estos argumentos para probar los efectos perniciosos que ocasiona no reconocer la existencia de un trabajo sexual, los grupos pro-derechos explican también cuáles serían los positivos en el caso contrario. Las ventajas se extenderían no solo a las personas que se dedican a la prostitución sino también al Estado y a la sociedad en general. Reconocerlas como trabajadoras mejoraría las condiciones de vida de estas personas, ayudaría a que ellas mismas se sintieran integradas y mejoraría su autoestima al no ser estigmatizadas por el grupo social. Este, a su vez, vería la prostitución como una actividad y no como una seña de identidad. Las prostitutas pasarían a ser mujeres que se dedican a prestar servicios sexuales en lugar de ser consideradas mu- 
jeres de mal vivir, deshonestas y perjudiciales para la sociedad.

La existencia de un trabajo sexual sería útil para el Estado en cuanto que controlaría el flujo de dinero que de hecho maneja el negocio de la prostitución y que, por falta de una legislación adecuada, está exento de fiscalización (Holgado,2008). Además, se garantizaría la estabilidad económica de aquellos Estados donde, en estos momentos, la prostitución y la industria del sexo son fuentes de financiación preferente.

Asimismo, la regulación de la prostitución mejoraría las condiciones de seguridad y salud de las personas que se dedican a ella y les ayudaría a negociar las mejoras de sus condiciones laborales, pero también implicaría que estas mujeres cumplieran con sus deberes laborales y fiscales pagando sus impuestos y, por lo tanto, beneficiando las arcas públicas. Por último, hay quienes desde posiciones pro-derechos sostienen que en épocas de crisis su regularización ayudaría a prevenir delitos en contra de la propiedad ya que muchas personas preferirían ejercer la prostitución antes que cometer un delito, máxime cuando la actividad además de ser una fuente de ingresos, sería la vía que les garantiza derechos sociales, laborales y económicos.

El Estado de bienestar debe atender y reconocer las demandas legítimas de sus ciudadanos cuando estos actúan de forma libre y no dañan ni perjudican a nadie. No debe entrar a valorar si éticamente es correcto o no, siempre que se cumplan los derechos reconocidos en la Constitución. Si la prostitución no viola ninguno de estos derechos y si, además, su reconocimiento como un trabajo es beneficioso tanto para las mujeres que la ejercen como para el Estado, no existe ninguna razón jurídica que impida su consideración como una actividad laboral más (Gay, Otazo, Sanz, 2003). Es más, algunas partidarias del trabajo sexual refuerzan esta argumentación afirmando que si el Estado no lo reconoce, lo que está haciendo es "imponer por ley el sexo gratuito", y esto "sentaría un precedente intervencionista en la sexualidad de la ciudadanía, obligándonos, a través de la tutela estatal, a tener una supuesta y estereotipada sexualidad "correcta" (Espejo, 2008, p. 128).

Frente a todos estos argumentos las abolicionistas afirman que la consideración de la prostitución como un trabajo convierte a los Estados en proxenetas, fomenta la desigualdad entre hombres y mujeres normalizando relaciones donde las mujeres asumen un estatus de subordinación respecto de aquellos, aumenta la trata de mujeres y beneficia la proliferación de mafias (Riera, 2009), (Raymond, 2004). Si el trabajo es un deber, además de un derecho, la normalización de la prostitución como una actividad laboral la convierte en una posible opción para entrar en el mercado laboral. El problema que esto conlleva es que en una sociedad en la que el trabajo es la llave para obtener los derechos de ciudadanía y la integración en el grupo social, tal y como reconocen los grupos pro-derechos, muchas mujeres se verán abocadas a elegir esta opción para poder acceder a los de- 
rechos que la ciudadanía comporta y para no sentirse excluidas y marginadas en la sociedad. En épocas de crisis, y dada la falta de oportunidades que muchas mujeres tienen para encontrar un trabajo, la prostitución será una opción legítima y las mujeres que pueden optar a ella y rehúsen a hacerlo podrán ser consideradas por el Estado como ciudadanas que eluden cumplir con sus obligaciones ${ }^{18}$. Además, afirmar que la no legalización de la prostitución niega la apertura a las mujeres para acceder a una parcela del mercado laboral, significa "aceptar que una de las misiones de estas en la vida social es dar placer sexual a los hombres, y asumir esto legitima al Estado para que lleve a cabo políticas que las mantengan en este tipo de actividad" (Fiss, 1995, p. 216).

\section{LA (NO) NEUTRALIDAD ÉtICA DEL RAZONAMIENTO A FAVOR DE LA REGULARIZACIÓN DE LA PROSTITUCIÓN COMO UN TRABAJO}

Según las feministas pro regularización la argumentación abolicionista se nutre de razones morales. Afirman que bajo el velo de querer defender el derecho a

18 Rehusar a una oferta "adecuada" de trabajo trae aparejadas consecuencias no deseables para un trabajador. Por ejemplo en España "Rechazar una oferta de empleo adecuada, ya sea ofrecida por el Servicio Público de Empleo o por las Agencias de Colocación sin fines lucrativos, salvo causa justificada, es motivo para que el Servicio Público de Empleo Estatal inicie un procedimiento sancionador por infracción grave que puede concluir con la pérdida de tres meses de prestación la primera vez que se incumple, de seis meses la segunda vez, y la extinción de todo el derecho si hay una tercer incumplimiento. " De Miguel (2015) sostiene: "Si una chica no encuentra trabajo, su hermano bien le podría recriminar su conducta: "papá y mamá lo están pasando mal, mamá ya está mayor, pero tú puedes colocarte de puta, no seas puritana, es un trabajo como otro cualquiera" (p. 168). la igualdad o el derecho a la dignidad de las mujeres se esconde una determinada concepción moral conservadora y el deseo de que el Estado dé una respuesta a la prostitución que sea acorde con la misma. Por el contrario, sostienen que su argumentación se basa en razones jurídicas y su propuesta para atender el problema de la prostitución supone una actitud por parte del Estado moralmente neutral. Pero ¿es la posición pro regularización una postura moralmente neutral? Aceptar sus razones ino implica que el Estado legitime una determinada forma de concebir como correctas o incorrectas las formas de organizar la sexualidad de la sociedad? ${ }^{19}$.

En este epígrafe mostraré que la postura pro regularización no es neutral desde el punto de vista ético ni cuando argumenta en contra de la prohibición de la prostitución ni cuando justifica su consideración como una actividad laboral más. Demostraré que: 1.- para justificar la no abolición de la prostitución asume que son válidos y sólidos los postulados

19 No discuto en este trabajo que la crítica realizada por las partidarias del trabajo sexual a las abolicionistas sea totalmente desacertada. Es más, sostengo que muchas de sus razones esconden juicios basados en los sentimientos y emociones que la prostitución puede generar instintivamente. En este sentido, el grupo abolicionista se ha preocupado más en contradecir a sus oponentes que en reflexionar si las razones habituales que ellas aportan resultan convincentes o no sin embargo es importante saber si las razones con las que condenamos o permitimos algo son buenas, con independencia de si las sabemos o intuimos como morales o inmorales. La crítica de nuestros propios argumentos es importante porque de resultar incorrectos pueden ser utilizados para apoyar causas que sí que son moralmente ilegítimas e injustas. 
de la denominada teoría ética del deber y además admiten, sin someterla a ninguna discusión, una determinada concepción moral de la sexualidad. Ambos extremos llevan a las partidarias pro-derechos a resolver la cuestión planteada desde una ideología liberal, y 2.- para justificar el reconocimiento de la prostitución como un "trabajo", además de partir de esos mismos postulados, añade argumentos propios del razonamiento mercantilista, razonamiento que no es inocuo desde el punto de vista ético tal y como están poniendo de manifiesto algunos de los más firmes representantes de la teoría de la justicia comunitarista.

Un análisis de la argumentación construida por este grupo, autodenominado proderechos, permite apreciar que la misma se sustenta sobre los siguientes pilares: 1.- las mujeres son libres para usar su cuerpo y su capacidad sexual como lo deseen. Si lo que quieren es comerciar prestando un servicio sexual a cambio de un dinero están en su derecho de hacerlo $^{20}$; 2.- en una relación consistente en el intercambio sexo por dinero no tiene por qué darse una relación de poder del hombre sobre la mujer ni una asimetría entre ambos; 3.- no toda relación de prostitución implica violencia o daños físicos y/o psicológicos; 4.- los Estados deben considerar la prostitución como un trabajo porque es una práctica útil, que beneficia a los participantes que lo demandan mutuamente, no perjudica a nadie y permite ganarse la vida a las personas que

20 "El bien jurídico supremo a proteger es el derecho a decidir con mayúsculas" (Espejo, 2008, p. 137), (Garaizábal, 2006, p. 72). lo solicitan. El Estado debe atender las demandas de sus ciudadanos teniendo en cuenta el beneficio que esto ocasiona. El número de preferencias satisfechas y su maximización es el criterio que debe guiar la actuación del Estado sin que deba entrar a valorar el contenido moral de las mismas porque esta es la respuesta más justa con la que se garantiza el derecho de igualdad de las mujeres y de todos los trabajadores.

Este razonamiento se apoya en varios conceptos: consentimiento, poder, daño y utilidad. Tal y como señala Agustín Malón:

en el paradigma ético del momento actual el consentimiento y el daño son las líneas argumentales más sólidas para juzgar una relación como permisible o no permisible. Junto a ellas se suelen incluir y mezclar otras como las relacionadas con el poder y la simetría o no entre los participantes, la coerción, instrumentalización y el uso del otro. (Malón, 2016, p. 55)

La ética racionalista o del deber, que es el punto de partida de este razonamiento, se nutre de argumentos fundamentalmente kantianos y utilitaristas. Para la deontología de Kant las relaciones humanas girarán en torno al principio moral del obligado respeto al otro ser humano, reconocido en su dignidad como ser racional y en su consideración como un fin en sí mismo y nunca como un medio. Para la postura utilitarista se ha de tener en cuenta las consecuencias de los actos, siendo estas éticamente relevantes si conducen al placer, el bienestar o la felicidad. 
Ahora bien, una comparación entre esta argumentación y la aportada por el grupo abolicionista muestra cómo ambas construyen sus razonamientos apoyándose en los mismos postulados, todos ellos propios de la ética del deber. Sin embargo, existen dos diferencias: la primera recae en la forma de entender los conceptos que forman parte de sus argumentos (consentimiento, daño, poder) y la segunda, consiste en la concepción de la sexualidad humana de la que parten. El grupo pro derechos mantiene una visión sensualista de las relaciones sexuales; consideran que la característica definitoria de las mismas es el placer hedonista, sensual, físico. Otros fenómenos, como el afecto, la intimidad etc. , pueden o no darse en estas relaciones, pero no son una nota esencial en las mismas $^{21}$. Por esta razón, cualquier relación sexual, si cumple con los parámetros antes dichos, es vista como intrínsecamente buena o al menos moralmente indiferente. Sin embargo, la posición abolicionista pareciera hacer uso de una concepción diferente de las relaciones sexuales donde la intencionalidad interpersonal entre los participantes juega un papel crucial. Por eso sostienen en su razonamiento la idea de que las relaciones sexuales entre prostituta y cliente no son relaciones "normales", o la idea de que si el Estado regulariza la prostitución como un trabajo "normalizaría" de cara a la sociedad esta práctica considerada "indeseable". Para las abolicionistas la sexualidad entre seres humanos requiere de la autoconsciencia como ser humano y de la consciencia de la exis-

$21 \quad$ La diferencia entre ambas concepciones ha sido analizada extensamente en Malón (2016, pp. 73 101) tencia de otras personas, esto es, exige "un reconocimiento mutuo como personas" (Malón, 2016, p. 90). Consideran que en la relación sexual habida en la prostitución hay una ausencia de intencionalidad en la prostituta que sea recíproca a la del cliente $y$, aunque la misma pudiera darse en un caso concreto, esta no surge espontáneamente de la persona. Esta concepción de la sexualidad estaría más próxima a las denominadas éticas de la virtud. A estas éticas les interesan más los ideales de la vida buena que el problema de los deberes morales.

Optar por una concepción moral de la sexualidad propia de la ética del deber o hacerlo por una propia de la ética de la virtud tiene consecuencias importantes a la hora de entender en qué consiste la educación moral. "Para la ética de la virtud, la educación moral será más un cultivo de hábitos y formación del carácter mediante el cultivo de ciertas cualidades ${ }^{22}$. Desde la tradición de la ética del deber se trataría de una educación racional e intelectual que buscaría la promoción de una cierta conformidad en las personas y su adhesión a las normas que rigen el comportamiento, vigentes en la comunidad" (Malón, 2016, p. 68). Por esta razón, en el razonamiento construido por las abolicionistas se incluyen términos como relaciones indeseables y se habla de la necesidad de "castigar" a los clientes de la

22 Esas cualidades son denominadas virtudes y consisten en "disposiciones de los seres humanos que integran elementos tanto emocionales como racionales y que tendrían la peculiaridad de ser beneficiosas para el hombre; sin ella el hombre o podría funcionar bien, no solo como individuo sino también como grupo" (Malón, 2016, p. 25). 
prostitución. También por esta misma razón la prostitución es considerada como una cuestión de género y se afirma la necesidad de educar a la sociedad para que interprete esta práctica social como una práctica que menosprecia a las mujeres al ser tratadas como objetos, como cuerpos que el hombre puede usar a su capricho. La benevolencia sería, para este grupo, una de las virtudes que convierten las relaciones sexuales en relaciones valiosas, dignas o estimables mientras que para las partidarias de no prohibir la prostitución toda conducta sexual es moralmente aceptable o permisible si es consentida y no provoca daños y esto no depende de la idea de un erotismo bueno sino de las consecuencias de esa conducta para las personas directa o indirectamente afectadas $^{23}$.

Por otra parte, algunas partidarias de permitir la prostitución consideran que los Estados, además de no perseguirla, deben considerar esta práctica como un trabajo más y señalan las similitudes que hay entre la prostitución y los contratos de prestación de un servicio. Sostienen su postura en dos pilares: uno es el respeto de la libertad individual, el segundo es la utilidad que ello conllevaría. La salvaguarda de la libertad individual es el principio moral que sustenta la teoría liberal ${ }^{24}$ y la

23 La benevolencia sería una virtud que consiste en tener sensibilidad hacia el malestar o el bienestar de los demás, que hace que las personas nos preocupemos del estado de los otros, que nos permite empatizar con "el otro" y actuemos en consecuencia para evitar su mal y procurar su bien.

24 Este principio aplicado al libre mercado dice: "que permitir a las personas que acuerden intercambios voluntariamente respeta su libertad" (Sandel, 2011, p. 90). utilidad es el principio moral fundamental de la teoría utilitarista ${ }^{25}$ y ambos configuran el llamado razonamiento mercantil. Este razonamiento es el que ha sido asumido como objetivamente neutral por las partidarias pro-derechos de las prostitutas y por otros teóricos del derecho ajenos al movimiento feminista (Ríos Raupp, 2004). Ahora bien, ces el razonamiento mercantilista moralmente neutro?

Tal y como dice Michael J. Sandel en su Teoría de la Justicia, actualmente casi todo tiene un precio; cada vez más bienes son objeto de compra y venta.

\begin{abstract}
El mercado ha pasado de ser una herramienta que los Estados usan para organizar la actividad productiva a convertirse en la forma de organizar todas las actividades humanas. Por eso, este autor afirma que se ha pasado de ser una economía de mercado a ser una sociedad de mercado y ambas cosas no se pueden equiparar, no son lo mismo. Si una economía de mercado puede ser una forma valiosa y eficaz para organizar la actividad productiva, una sociedad de mercado es una manera de vivir en la que los valores mercantiles rigen todas las actividades humanas. Es un lugar donde las relaciones sociales están hechas a imagen del mercado. (Sandel, 2013, p. 18).
\end{abstract}

25 El argumento utilitarista a favor de los mercados sostiene "que el libre mercado promueve el bienestar general cuando dos acuerdan un trato, ambos ganan, Mientras el trato beneficie a los dos sin perjudicar a nadie, incrementará la utilidad general" (Sandel, 2011, p. 90). 
Esta transformación ha provocado también una cambio en la economía: de ser una ciencia encargada de estudiar las relaciones de producción y de consumo de los bienes materiales ha pasado a extender su ámbito de análisis para explicar el comportamiento humano en general, la forma en la que las personas interactúan y los principios en virtud de los cuales se toman las decisiones ${ }^{26}$. Pero para explicar su nuevo ámbito de estudio, tarea mucho más ambiciosa, usa los mismos valores y las mismas reglas que ha empleado a la hora de explicar el ámbito de la producción y el consumo de bienes materiales. Todo el comportamiento humano es interpretado partiendo de la idea de que los individuos siempre que toman una decisión lo hacen después de sopesar los costes y los beneficios de las opciones que se ofrecen y suelen elegir la que se considera que proporcionará el mayor bienestar o la máxima utilidad.

Sandel aporta numerosos ejemplos de cómo se ha llegado a mercantilizar relaciones sociales que antes se regían por normas y principios ajenos al ámbito económico. Actualmente el valor del dinero, leyes como la de la oferta y la demanda o la ley de precios son usados para regular aspectos que afectan a la sanidad, a la educación, a las relaciones de amistad, aspectos de la vida social que antes se regían por otros principios y por otros valores distintos a aquellos. Ahora hay padres e instituciones que pagan a los estudiantes para que saquen buenas

26 En 1976 Gary Becker (1976) sostuvo: "la gente actúa para maximizar su bienestar, cualquiera que sea la actividad que desarrolle" (p. 3). calificaciones; así se garantiza que la inversión de tiempo y de dinero que se emplea en su formación sea beneficiosa y eficaz; abundan las empresas que ofrecen los más variopintos servicios a cambio de un precio, desde escribirte el discurso que vas a dar en la boda de tu mejor amigo hasta presentar disculpas en tu nombre cuando has agraviado a una persona y no deseas hacerlo personalmente. Los Estados pagan a las personas obesas para que adelgacen tras valorar que el coste sanitario que la obesidad ocasiona a las arcas públicas es mucho mayor que el pago de estos incentivos; se paga por hacer de cobaya humana con el fin de probar la seguridad de una nueva sustancia para una compañía farmacéutica, etc. Esta forma de regular las relaciones trae aparejadas consecuencias económicas positivas, se ahorran costes y se consiguen los objetivos perseguidos en la mayoría de los casos. Todos los implicados salen beneficiados.

Los gobiernos actuales a la hora de atender las demandas de sus ciudadanos utilizan, en la mayoría de las ocasiones, el razonamiento mercantil como la forma para decidir su legalización o su prohibición y ello porque aún está en vigor la idea de que la economía es una ciencia neutral desde el punto de vista moral ${ }^{27}$. Se presupone que el mercado es el medio más idóneo para regular las relaciones

27 Para muchos estudiosos los intercambios económicos no tienen ninguna trascendencia moral y entre esos intercambios incluyen el comercio sexual, ver: Saiz Viadero (1983, p. 9). Para un análisis de cómo se afianzó la idea de que la Economía significó una ruptura con la Filosofía moral, ver: Atilano Pena y Sánchez Santos (2007a, 2007 b). 
sociales "porque es eficaz para maximizar su utilidad, respeta la libertad de las personas y se rige por reglas asépticas desde el punto de vista moral" (Sandel, 2013, p. 21) ${ }^{28}$. Los Estados democráticos, plurales y laicos no deben imponer una moral a sus ciudadanos; de ahí que el razonamiento mercantil se aprecie como la forma más idónea de justificar las respuestas jurídicas que el Estado actual debe dar a los problemas sociales. Pero cuando el mercado se convierte en el criterio que debe guiar la actuación del Estado y el razonamiento mercantil en el método adecuado para justificar sus respuestas jurídicas, aquel deja de ser un instrumento y pasa a convertirse en una norma (Sandel, 2013), (Lechat, 2004).

La expansión de los mercados a esferas anteriormente reguladas por otros valores y otras reglas no mercantiles hace que esos valores queden desplazados. Este desplazamiento al menos provoca tres consecuencias importantes:

En primer lugar, los principios del razonamiento mercantil no siempre son eficaces en el momento en que se aplican a ámbitos no estrictamente económicos, o sea cuando regulan prácticas sociales ajenas a esa esfera. Al respecto, Sandel nos aporta un ejemplo significativo en relación con la operatividad de la ley de precios cuando es aplicada para regular los horarios de la recogida de los niños en una guardería en EE. UU. Los padres llegaban siempre tarde a recogerlos. Esto

28 En este mismo sentido ver: Friedman (1956). Sobre la neutralidad de la Economía y las causas que han motivado ver: Gómez (1997). ocasionaba que las cuidadoras permanecieran en el centro más tiempo que el que su jornada laboral les obligaba. Para evitar esta situación, se estableció una penalización pecuniaria a los padres que llegaran tarde; con ella se intentaba concienciarlos de que su conducta constituía una falta de respeto hacia las trabajadoras del centro. Si la ley de precios hubiese sido efectiva, al subir el precio los retrasos deberían haber mermado puesto que a mayor precio menor consumo del bien, en este caso del servicio. Sin embargo, las consecuencias fueron diametralmente opuestas. Los padres asumieron que al pagar la penalización habían adquirido el derecho de llegar tarde, los retrasos fueron mayores y el sentido de responsabilidad, que era el valor con el que hasta entonces se regulaba esa práctica, quedó desplazado. La obligación moral de ser puntual quedó sustituida por el valor económico (Sandel, 2013).

En segundo lugar, en una sociedad donde todo tiene un precio, donde el dinero se convierte en un valor primordial, las personas que disponen de él serán valoradas positivamente por la sociedad y podrán acceder a todo cuanto deseen, mientras que las personas que no dispongan de recursos serán valoradas negativamente y cada vez dispondrán de menos cosas a las que acceder. Si no existe igualdad de oportunidades para acceder a los puestos de trabajo ni a las fuentes de producción, si no existe igualdad en casi ningún ámbito de la vida, el hecho de que todo tenga un precio implica ahondar y agravar dichas diferencias. Por otra parte, en las sociedades donde la desigualdad es cada 
vez mayor, "el libre mercado, para quienes no tienen mucho donde elegir, no es tan libre" (Sandel, 2011, p. 97).

En tercer lugar, hay relaciones interpersonales que se consideran valiosas sin necesidad de que estén incorporadas en el mercado. Es más, se aprecian precisamente porque se mantienen alejadas de la esfera económica y no tienen un valor monetario. Si se las pusiera un precio no serían estimadas de la misma forma (Anderson,1993). La amistad, afirma el filósofo americano, es un caso paradigmático, la compra de un amigo es posible, pero el hecho mismo de que tenga un precio hace que la relación no se valore de la misma forma que si hubiera surgido mediando otros valores como la simpatía, la afinidad, el respeto etc. Hay prácticas que el dinero "corrompe" porque nuestra actitud ante ellas cambia precisamente "porque el dinero es la forma de adquirirlas" (Sandel, 2013, pp. 40 42). Esto sucede porque los valores con los que se interpreta y se da sentido a esas relaciones son distintos al económico y si son desplazados por este las relaciones se degradan; nuestra forma de participar en ella también. Los mercados y el razonamiento mercantil que ensalza los valores de mercado no son meros mecanismos, encierran normas "presuponen y promueven ciertas maneras de valorar los bienes que se intercambian" (Sandel, 2011, p. 300), (Sandel, 2013, p. 17).

Cuando el Estado regula cuestiones que tienen que ver con este tipo de prácticas sociales y aplica el razonamiento mercantil y los valores monetarios para darles una respuesta no es moralmente neutral porque está transformando la forma de apreciar y de valorar esas prácticas que tiene la sociedad y está estableciendo una nueva forma de ser interpretadas, les otorga un significado nuevo e influye en la actitud que los ciudadanos tienen frente a ellas (Honneth, 2006). En definitiva, está imponiendo el valor monetario sobre el resto de los valores posibles, está marcando, además, que esta es la forma justa de interpretar la práctica y esto no es para nada neutral ${ }^{29}$. El autor de Justicia ¿hacemos lo que debemos? da varios ejemplos para ilustrar este hecho. Cuando se paga a las personas para que adelgacen, las normas jurídicas que establecen esos incentivos están valorando el cuidado de la salud como un bien que se puede comprar; cuando se articulan normas jurídicas que establecen el pago a los estudiantes por sus rendimientos está valorando la educación como un bien que también tiene un precio. El dinero desplaza otros valores como el respeto, la solidaridad, el deber de cuidar el propio cuerpo, etc. ${ }^{30}$

Llegados a este punto, Sandel sostiene que el desplazamiento de unos valores

29 Sandel (2013) entiende "corrupción" como degradación de la relación o de la práctica social, porque se les "da un valor inferior al que les corresponde" (p. 42). Una visión similar a la de este autor aplicada a la prostitución la tiene Georg Simmel (1971) cuando sostiene que en todo proceso donde se equipara "individuo=dinero", y la prostitución es un ejemplo de ello, se ocasiona una terrible "degradación de la personalidad" (p. 113).

30 El desplazamiento de valores cívicos y culturales por los valores mercantiles en la vida íntima y las repercusiones negativas que esto conlleva es también estudiado por: Russel (2011, pp. 25-70). Cómo el espíritu mercantilista ha invadido al feminismo es analizado por Rubio (2008, pp. 25-48). 
por otros a la hora de interpretar las prácticas sociales nos debería llevar a plantearnos si se puede estar de acuerdo con las repercusiones que esto conlleva; así, por ejemplo, el autor se pregunta:

\begin{abstract}
¿Debe importarnos que los padres dejen de sentirse culpables por recoger tarde a los niños de la guardería y vean su relación con la cuidadora en términos instrumentales? ¿Debe importarnos que pagando a los obesos por adelgazar estos terminen viendo su salud como una fuente de ingresos en lugar de considerar que tienen el deber de cuidar su cuerpo? (Sandel, 2013, p. 95).
\end{abstract}

Cuando se justifica la consideración de la prostitución como un trabajo y para ello se aportan argumentos propios del razonamiento mercantil hay que tener en cuenta que estos no son neutrales desde el punto de vista moral. Es presuponer que la concepción que sostiene que la sexualidad es algo que maximiza la utilidad, es moralmente la más apropiada y que la manera justa de que el Estado la regule es satisfacer esta concepción sin cuestionarla, ampliarla o complicarla. Tal y como señala Ana Rubio (2008), "no cabe neutralidad al decidir el contenido de las normas" (p. 82). Se puede justificar la mercantilización de la sexualidad alegando que en sociedades mercantiles, como la nuestra, se sacan al mercado y se convierten en mercancía muchos servicios que antes se desarrollaban en el marco de las estructuras comunitarias y familiares, pero hay que ser conscientes de que este tipo de argumento no es moralmente neutral y que implica responder también otros interrogantes: ¿debe importarnos que legalizar la compra venta de servicios sexuales como un trabajo nos haga apreciar las relaciones sexuales como relaciones mercantiles? ¿Debe importarnos que las personas que se dedican a prestar servicios sexuales sean vistas como fuente de ingresos en lugar de seres humanos? ¿El hecho de legalizar y normalizar la compra venta de la sexualidad cambiaría el sentido con el que la sociedad quiere construir sus formas de vida sexual? ¿Fomentaría actitudes indeseables respecto del sexo? ¿No se debería evitar la introducción en los ordenamientos jurídicos de relaciones donde la sexualidad tenga un precio? ¿Puede el hecho de legitimar relaciones sexuales compradas transformar desvalorizando actitudes y normas que merecen protegerse? Para contestar a esas preguntas el razonamiento mercantil debe someterse a la moral y el debate sobre la prostitución debe analizar también razones morales ${ }^{31}$.

Puede que, una vez sometida la prostitución a un debate donde las razones morales entran a formar parte, no se llegue a una única solución; también puede ser que se termine aceptando los valores monetarios como los más adecuados para regular las formas de vida sexual, o todo lo contrario; pero, en todo caso, la solución que se dé será el resultado de una discusión abierta donde se haya justificado si nos parece correcto el juicio ético que establece que las razones morales deben quedar fuera del territorio del sexo y si son los valores mercantiles los

\footnotetext{
31 Para analizar las relaciones entre la Economía y la
} Filosofía moral ver: Hausman y McPherson (2017). 
más correctos para construir las formas sexuales en las sociedades actuales.

\section{CONCLUSIONES}

Los objetivos de este trabajo eran dos. Por un lado, sistematizar y analizar los argumentos con los que se está defendiendo dentro del feminismo la cuestión de cuál es la respuesta que los Estados deben dar a la prostitución. Por otro lado, mostrar que el razonamiento construido por las partidarias de que la prostitución debe ser regulada como una actividad laboral más no es, tal y como pretenden sus partidarias, neutral desde el punto de vista ético y ello porque para justificar la no prohibición de esta práctica social parten de asumir como válidos para tratar esta cuestión los postulados de las llamadas éticas del deber en detrimento de los postulados de las éticas de la virtud. Además, las razones con las que se justifica que la prostitución debe ser reconocida como un trabajo más se sustentan en un razonamiento mercantilista que tampoco es inocuo desde el punto de vista ético.

A la luz de lo expuesto, se puede concluir que en el debate sobre la prostitución ninguna de las posturas intervinientes mantiene posiciones moralmente neutrales. Sin embargo, ambas plantean la cuestión como si se tratase de un problema jurídico, político y económico subestimando la reflexión ética que debería preceder en orden lógico a las demás discusiones. Esta reflexión debería abarcar el análisis de las limitaciones y contradicciones que puede tener la ética del deber y si es necesario o no completar sus postulados con los de la ética de la virtud a la hora de resolver cuestiones tan controvertidas y complejas como es la prostitución. Debería, además, estudiar si el comportamiento sexual debe ser enjuiciado con los mismos elementos con los que se valora cualquier otra relación humana o si existen razones para considerar que dicho comportamiento posee una estructura y naturaleza específica que justifica su valoración a través de una moral sexual especial.

\section{REFERENCIAS}

Anderson, E. (1993). Value in ethics and economics. Cambridge, Massachusetts: Harvard University Press.

Agustín, L. M. (2004). Trabajar en la industria del sexo, y otros tópicos migratorios. Donostia, España: Tercera Prensa-Hirrugarren Prentsa.

Agustín, L. M. (2008). Trabajo y ciudadanía: movimientos pro derechos de las trabajadoras del sexo. En J. L. Solana y E. Acien. (Eds. ), Los retos de la prostitución: estigmatización, derechos y respeto (pp. 31-42). Granada, España: Comares.

Arella, C. , Fernández, C. , Nicolás, G. , y Vartabedián, J. (2007). Los pasos (in)visibles de la prostitución. Estigma, persecución y vulneración de derechos de las trabajadoras sexuales en Barcelona. Barcelona, España: Virus Editorial.

Atilano Pena, J. , y Sánchez Santos, J. M. (2007a). Los fundamentos morales de la Economía: una relectura del problema de Adam Smith. Revista de Economía Institucional, 9 (16), 63-87.

Atilano Pena, J. , y Sánchez Santos, J. M. (2007b). El problema de Smith y la relación entre moral y economía, Isegoría, 6, 81-103.

Aucía, A. (2008). Trabajo sexual: dificultades de concebir como trabajo aquello que la cultura degrada. Mora, 14, 47-151.

Barry L. (1988). Esclavitud sexual de la mujer. Barcelona, España: La Sal. 
Becker, G. S. (1976). The Economic Approach to Human Behavior. Chicago, Estados Unidos: University of Chicago Press.

Brufao Curiel, P. (2008). Prostitución y políticas públicas: entre la reglamentación, la legalización y la abolición. Madrid, España: Fundación Alternativas.

Cobo, R. (2013). Claves para un análisis feminista de la prostitución. Rev. Con la A, 26. Recuperado de http://www. amecopress. net/ spip. php?article10975 el día 23 de mayo del año 2018.

De Lora, P. (2007). ¿Hacernos los suecos? La prostitución y los límites del Estado.

Doxa, 30, 451 470.

De Marneffe, P. (2010). Liberalism and prostitution. Oxford, Reino Unido: Oxford University Press.

De Miguel, A. (2015). Neoliberalismo sexual. El mito de la libre elección. Valencia, España: Cátedra.

Espejo, B. (2008). La prostitución desde una visión transexual. En I. Holgado Fernández. (Ed. ), Prostituciones. Diálogos sobre sexo pago (pp. 123-138). Barcelona, España: Icaria

Falcón, L. (1992). El infierno de las mujeres. Poder y libertad, 19, 1-5.

Falcón, L. (2012). Prostitución, la esclavitud aceptada. Nuestra Bandera, 232, 79-92.

Falcón, L. (2014). Feminismo en tiempo de crisis. Rauden, Revista de Estudios de las mujeres, 2, 351-366.

Fiss, O. (1995). ¿Qué es el feminismo? Doxa, 14, 319-335.

Frazer, N. (1996). Redistribución y reconocimiento: hacia una visión integrada dela justicia del género. RIFP, 8, 18-40.

Friedman, M. (1956). The quantity theory of money: a restament. En M. Friedman. (Ed. ), Studies in the Quantity Theory (pp. 3-21). Chicago, Estados Unidos: The University Press of Chicago.
Gamba, S. (marzo de 2008). Feminismo: historia y corrientes. Mujeres en Red. El Periódico Feminista. Recuperado de: http://www. mujeresenred. net/spip. php?articlel397

Garaizábal, C. (julio de 2006). Por los derechos de las trabajadoras del sexo. Viento Sur: por una izquierda alternativa, 87, 62-72.

Garaizábal, C. (2008). Las prostitutas toman la palabra. Las vicisitudes de su construcción como sujetos sociales. En I. Holgado Fernández. (Ed. ), Prostituciones. Diálogos sobre sexo pago (pp. 95-110). Barcelona, España: Icaria.

Garaizábal C. , (Diciembre de 2009). Debates feministas sobre sexualidad. En M. Belbel (Presidente), Granada 30 años después: aquí $y$ ahora. Ponencia llevada a cabo en las Jornadas feministas organizadas por la Asamblea de Mujeres de Granada "Mariana Pineda", Granada.

García, C. (2007). El derecho a decidir. Debate, 2, 25-29.

Gay, S. , Otazo, E. , y Sanz, M. (2003). ¿Prostitución = profesión?: una relación a debate. Derecho Comparado, 106, 13-27.

Giménez Barbat, T. (2008). Prostitución femenina. Claves de Razón Práctica, 187, 12-16.

Gimeno, B. (2012). La prostitución. Aportaciones para un debate abierto. Barcelona, España: Bellaterra.

Gómez, F. J. M. (1997). Economía y valores humanos. Madrid, España: Ediciones Encuentra.

González, M. (25 de febrero de 2012). La prostitución en el imaginario social [Mensaje

en el blog Revista Feminista Brujas 32 Atema]. Recuperado de http://revistafeministabrujas32atem. blogspot. com. es/2012/02/ la-prostitucion-en-el-imaginario-social. html

Hausman, D. y McPherson, M. (2017). Economic Analysis, Moral Philosophy and Public Policy. Cambridge, Reino Unido: Cambridge University Press.

Holgado Fernández, I. (2008). El que paga por pecar. Hombres clientes de sexo pago. En I. 
Holgado Fernández. (Ed. ), Prostituciones. Diálogos sobre sexo pago (pp. 139-159). Barcelona, España: Icaria.

Holgado Fernández I. (2008a). Todas las voces para un solo concierto feminista. En I. Holgado Fernández Isabel. (Ed. ), Prostituciones. Diálogos sobre sexo pago (pp. 7-39). Barcelona, España: Icaria.

Honneth, A. (2006). Reidificación, Madrid, España: Katz.

Juliano, D. (2005). El trabajo sexual en la mira. Cuadernos Pagu, 25, 79-106.

Juliano, D. (2008). El pánico moral y la criminalización del trabajo sexual. En I. Holgado Fernández. (Ed. ), Prostituciones. Diálogos sobre sexo pago (pp. 111-122). Barcelona, España: Icaria.

Lechat, N. (2004). Economía moral. En A. D. Cattani. (Ed. ), La otra economía (pp. 165-172). Buenos Aires, Argentina: Altamira.

Lipszyc, C. (2 de noviembre de 2003). Mujeres en situación de prostitución: ¿trabajo o esclavitud sexual?, Cladem. Recuperado de: http://www. ciudadaniasexual. org/boletin/ bll/Mujeres situacion Prostitucion. pdf

López Riopedre, J. L. (2012). Una aproximación etnográfica a la prostitución cuando las trabajadoras sexuales hablan de los clientes. RES, Revista Española de Sociología, 18, 31-62.

Lorenzo Rodríguez-Armas, M. (2008). Constitución española, estado social y derechos de las mujeres que ejercen la prostitución. Feminismos, 12, 253-270.

Loviband, S. , y Sefchovich, S. (1992). Feminismo y postmodernismo. Debate feminista, (5), 129-164.

Lucas, R. E. Jr. (1984). Expectations and Neutraly of Money. Journal of Economic Theory, 4 (2), 103-124.

Malón, A. (2016). Ética sexual contemporánea. Aspectos pedagógicos y límites. Valencia, España: Tirant Humanidades.
Maqueda Abreu, M. L. (2006). Feminismo y prostitución. $3^{a}$ ed. , Madrid, España: Travel S. L.

Maqueda Abreu, M. L. (2009). Prostitución, feminismos y derecho penal. Granada, España: Comares.

Maqueda Abreu, M. L. (2010). Cuando el Estado acosa a las mujeres. (A propósito del derecho a una sexualidad no coercitiva). En D. Heim y E. Bodelón. (Coord. ), Derecho, género e igualdad. Cambios en las estructuras jurídicas androcéntricas (pp. 249-260). Barcelona, España: Grupo Antígona, Universidad Autónoma de Barcelona.

Mestre i Mestre, R. (2007). Trabajo sexual, igualdad y reconocimiento de derechos. En $\mathrm{R}$. Serra Cristóbal. (Coord. ), Prostitución y trata. Marco jurídico y régimen de derechos (pp. 13-42). Valencia, España: Tirant Lo Blanch.

Mestre i Mestre, R. (2008). Trabajo sexual e igualdad. En I. Holgado Fernández. (Ed. ), Prostituciones. Diálogos sobre sexo pago (pp. 55 72). Barcelona, España: Icaria.

Mohanty, J. (1990). Feminist Encourents: locating the Politics of Experience. En A. Philips. (Ed. ), Feminism and Politics (pp. 254-272). Oxford, Nueva York: Oxford University Press,

Montero, J. , y Zabala, B. (2006). Algunos debates feministas en torno a la prostitución. Viento Sur, 87, 97-103.

Ngozi Adichie, G. (2015). Todos deberíamos ser feministas. Barcelona, España: Penguin Random House.

Pateman, C. (1995). El contrato sexual. Barcelona, España: Anthropos.

Pheterson, G. (1992). Nosotras las putas. Madrid, España: Talasa.

Pheterson, G. (1996). El prisma de la prostitución. Madrid, España: Talasa.

Pitch, T. (2010). Sexo y género de y en el derecho: el feminismo jurídico. Anales de la Cátedra de Francisco Suárez, 44, 435-459.

Raymond, J. G. (2004). 10 razones para no legalizar la prostitución. Madrid, España: 
Partido Comunista de España. Recuperado de http://www. pce. es/secretarias/secmujer/ pl. php?id=688

Riera, M. (2009). Abolicionismo, regulacionismo y prohibicionismo. Entrevista a Lara Padilla. El Viejo Topo, 262, 32-37.

Ríos Raupp, R. (2004). Apuntes para un derecho democrático de la sexualidad. En C. Cáceres, T. Trasca, M. Pecheny, y V. Teto. (Eds. ), Ciudadanía sexual en América Latina. Abriendo el debate (167-187). Perú: Universidad Peruana Cayetano Heredia.

Rodríguez M. (Ed. ). (2015). Sin género de dudas. Logros y desafíos del feminismo hoy. Madrid, España: Biblioteca Nueva.

Rodríguez Martínez, P. (2008). Género, inmigración y trabajo en las sociedades posmodernas. En I. Holgado Fernández. (Ed. ), Prostituciones. Diálogos sobre sexo pago (pp. 41-54). Barcelona, España: Icaria.

Romalho, N. (2012). O trabalho sexual: discursos e prácticas dos asistentes sociais em debate. Sexualidad, Salud y Sociedad, Revista Latinoamericana, 12, 64-91.

Rorty, R. (2003). Feminismo, ideología y deconstrucción. En S. Zizek. (Comp. ), Ideología: un mapa de la cuestión (pp. 253-263). Buenos Aires, Argentina: Fondo de Cultura Económica.

Rubio, A. (2008). La teoría abolicionista de la prostitución desde una perspectiva feminista. En I. Holgado Fernández. (Ed. ), Prostituciones. Diálogos sobre sexo pago (pp. 7394). Barcelona, España: Icaria.

Ruiz, A. E. C. (2001). De cómo el derecho nos hace mujeres y hombres. Revista da Faculda de Direitto da UFPR, 36, 7-15.

Russell Hochschild, A. (2011). La mercantilización de la vida intima. Madrid, España: Katz.
Sandel, M. J, (2011). Justicia. ¿Hacemos lo que queremos? Barcelona, España: Debate.

Sandel, M. J. (2013). Lo que el dinero no puede comprar. Barcelona, España: Debate.

Saiz Viadero, J. R. (1983). Conversaciones con la Mary Loly. Santander, España: Puntal.

Simmel, G. (1971). On individual and Social Forms. Chicago, Estados Unidos: The University Chicago Press.

Torres San Miguel, L. (2008). ¿Por qué la prostitución no es un trabajo? En Pérez Freire, S. , Fontecha López, A. , y Carracedo Bullido, R. , Prostitución: análisis y opciones para su erradicación, León, España: Asociación Flora Tristán, pp. 35-67.

Unzueta, M. (1992). Feminismo y garantismo: ¿una teoría del derecho feminista? Anuario de Filosofía del Derecho, 9, 75-89.

Valcárcel, A. (1991). Sexo y filosofía, sobre mujer y poder. Barcelona, España: Anthropos.

Valcárcel, A. (1997). La política de las mujeres. Madrid, España: Cátedra.

Valcárcel, A. (2001). La memoria colectiva y los retos del feminismo. Santiago de Chile, Chile: Unidad Mujeres y Desarrollo, Cepal-Eclac.

Villacampa Estiarte, C. (2012). Políticas de criminalización de la prostitución: un análisis crítico de fundamentación y resultados. Revista de Derecho Penal y Criminología, 3(7), 81-142.

Wijers, M. (2004). Delincuente, víctima, mal social o mujer trabajadora: perspectivas legales sobre la prostitución. En R. Osborne. (Ed. ), Trabajador@sdel sexo. Derechos,migraciones y tráfico en el s. XXI (pp. 209-222). Barcelona, España: Bellaterra. 